\title{
Complex Processing of Phosphogypsum - a Way of Recycling Dumps with Reception of Commodity Production of Wide Application
}

\author{
Denis Lutskiy ${ }^{1 *}$, Tatiana Litvinova' ${ }^{1}$, Alexandr Ignatovich' ${ }^{1}$, Igor Fialkovskiy ${ }^{1}$ \\ 1 Saint Petersburg Mining University, Department of Physical Chemistry, 199106, Saint-Petersburg, 21 Line 2, \\ Russian Federation \\ * Corresponding author's e-mail: denis.lutskii@gmail.com
}

\begin{abstract}
The article analyzes the information on modern developments in the utilization of phosphogypsum. Only a few directions give the prospect of large-scale use of both freshly formed phosphogypsum and phosphogypsum accumulated in dumps. Under the conditions of the Russian Federation, it is promising to use phosphogypsum for the production of building materials, as well as for agriculture, for reclamation of soil and the creation of mounds of a certain type. The possibility of using phosphogypsum as a raw material for obtaining rare-earth elements is shown.
\end{abstract}

Keywords: phosphogypsum, utilization, building materials, agriculture, rare earth elements, conversion.

\section{INTRODUCTION}

The state strategy of sustainable development of Russia proclaims in the environmental sphere the preservation and restoration of natural ecosystems, the stabilization and improvement of the quality of the environment, the organization of processing as well as utilization of liquid and solid wastes.

Inclusion of wastes and by-products in the production cycle of operating enterprises should be the basic principle of a rational use of natural resources. At the same time, a number of the most important tasks is being solved: the fuller use of raw materials, the creation of new products, and improvement of the ecological situation in the region.

It is known that the raw material base for many branches of the chemical industry is depleted and the question of involving both raw materials with a low content of useful components and production waste in production is becoming more urgent.

In favor of the development of technogenic deposits, a number of economic reasons can also be cited: the fields are accessible, since they are located in the regions with developed infrastructure, do not require preliminary preparation (crushing, grinding), and they allow obtaining a sufficiently wide range of required useful products.

Processing tailings and dumps in the chemical industry is becoming a top priority worldwide, as their clusters have reached certain critical values. It is necessary to take into account the fact that waste products put a dead weight on the cost of production of enterprises and often become a kind of "brake" for increasing the productivity of production.

All of the above also concerns phosphogypsum - a large-tonnage waste of phosphoric acid production by the sulfuric acid method. According to the research conducted by the Institute of Fertilizers and Insectofungicides of I.N. Samoilov, in Russia, at least 12 plants of phosphate fertilizers work on sulfuric acid technology. For one ton of $\mathrm{P}_{2} \mathrm{O}_{5}, 46$ tons of phosphogypsum are formed. In the dumps of each plant, 10-12 million phosphogypsum was accumulated, the amount of which continues to increase annually by 0.81 million tons. A similar situation exists in the phosphate fertilizer plants of Ukraine, Belarus and Uzbekistan (Zinkovskaya 2010). In addition, the phosphogypsum dumps significantly influence the 
biosphere. Thus, for example, the research of the Moscow State University of M.V. Lomonosov showed that the soils within a radius of up to $2 \mathrm{~km}$ from the phosphogypsum dumps of the Voskresensky plant for the production of mineral fertilizers are contaminated with elements that make up the waste.

Currently, the average level of useful use of this industrial waste is no more than $2.0 \%$. The need to involve dumps of phosphogypsum and the industial wastes similar in composition and properties in the processing is obvious (Gordashevsky et al. 1987).

In the article, the existing methods and technologies for the utilization of gypsum wastes in various industries, as well as the methods and approaches for complex processing of phosphogypsum and gypsum wastes with obtaining a wide marketable product are considered.

\section{COMPOSITION AND PROPERTIES OF PHOSPHOGYPSUM}

Phosphogypsum is a byproduct of phosphoric acid production which contains $92 \%$ of gypsum. It should be noted that phosphogypsum contains $0.4-0.6 \%$ of rare earth elements, including the most valuable ones: neodymium, samarium, terbium, ytterbium, erbium, dysprosium (Laskorin et al. 1986). Table 1 presents the chemical composition of phosphogypsum obtained during the processing of apatite concentrate.

As seen from the data in the Table 1, apart from the main substance, phosphogypsum contains various impurities that enter it at the stage of decomposition of apatite concentrate with a mixture of sulfuric and phosphoric acids.

Phosphogypsum is a finely dispersed powder, partially crushed, containing up to $40 \%$ moisture (with a dihydrate process) or up to $25 \%$ moisture (with a hemihydrate process); even the phosphogypsum dried at a temperature of $200{ }^{\circ} \mathrm{C}$ reaccumulates moisture during storage. The phosphogypsum treated at $800^{\circ} \mathrm{C}$ practically does not absorb moisture from the air.
High dispersion of phosphogypsum (specific area $3500-3800 \mathrm{~cm}^{2} / \mathrm{g}$ ) allows to exclude from the technological process crushing and coarse grinding. At the same time, the high humidity of phosphogypsum (up to $40 \%$ ) complicates its transportation and preparation and leads to significant fuel consumption for drying.

The presence of water-soluble phosphorus and fluorine-containing impurities in phosphogypsum complicates the processing of waste in comparison with the processing of natural gypsum stone, causing the need for washing, neutralization, etc.

\section{WAYS OF PHOSPHOGYPSUM UTILIZATION IN VARIOUS INDUSTRIES}

The problem of gypsum wastes and specifically phosphogypsum utilization is being tried since the end of the 20th century. In Russia, a large set of works has been carried out to study the properties of phosphogypsum, its processing technologies and uses in the national economy. All known methods of phosphogypsum and gypsum wastes utilization can be divided into several groups, according to the degree of processing depth of technogenic raw materials:

1) application of phosphogypsum without any processing;

2) application of phosphogypsum as a raw material or technological additive in the existing production cycle;

3 ) processing of phosphogypsum in order to extract valuable components, for example, rareearth metal compounds;

4) processing of phosphogypsum for a number of marketable products.

\section{APPLICATION OF PHOSPHOGYPSUM WITHOUT ANY PROCESSING}

\section{Application in agriculture}

Large-scale studies on the agroecological efficacy of phosphogypsum have been carried

Table 1. Chemical composition of phosphogypsum obtained during processing of apatite concentrate of Kola and Kovdorsk deposits

\begin{tabular}{|l|c|c|c|c|c|c|c|}
\hline \multirow{2}{*}{ Apatite deposit } & \multicolumn{7}{c|}{ Chemical composition, \% } \\
\cline { 2 - 8 } & $\mathrm{CaO}$ & $\mathrm{SO}_{3}$ & $\mathrm{P}_{2} \mathrm{O}_{5}$ & $\mathrm{Ln}_{2} \mathrm{O}_{3}$ & $\mathrm{Fe}_{2} \mathrm{O}_{3}$ & $\mathrm{MgO}$ & $\mathrm{F}$ \\
\hline Kola & $39-40$ & $56-57$ & $1.0-1.2$ & $0.50-0.06$ & - & - & $0.30-0.40$ \\
\hline Kovdorsk & $39-41$ & $55-56$ & $1.4-1.5$ & $0.14-0.15$ & 0.10 & $0.03-0.08$ & 1.07 \\
\hline
\end{tabular}


out in many regions of Russia, including the Rostov Region and the Stavropol Territory. The administration of the Rostov region drew attention to the introduction of this effective method in agricultural production. On January $20^{\text {th }}, 2012$, the Rostov Region Government adopted Resolution No. 33 "On the procedure for granting subsidies to agricultural producers to recover part of the costs of purchasing and delivering phosphogypsum for chemical melioration of and reclamation of lands". It approved the Regulations on the procedure for granting subsidies to agricultural producers to recover $70 \%$ of the costs of purchasing and delivering phosphogypsum for chemical melioration.

The results of the measures taken have shown high efficiency in the amelioration of salted and acidic soils (Medvedev et al. 2015, Zinkovskaya 2010, Volkova 2017), as well as land reclamation after oil products contamination.

\section{Application in road construction}

In road construction, phosphogypsum is used for the production of hydraulic additives and material for the creation of a road foundation (Sizyakov et al. 2012).

When the optimal amount (10-25\%) of the stabilizing additive of phosphogypsum dihydrate is introduced, the strength properties of soils are increased by $10-35 \%$. However, it is important to note that only fresh phosphogypsum is suitable for these purposes.

\section{Application of phosphogypsum as a raw material or processing additive in the existing production cycle}

The physicochemical properties of phosphogypsum allowed to use it in the cement and the construction industry (Akhmetov et al. 1986, Bazhenov et al. 1986, Boldyrev et al. 1983, Vereshchagin 1987).

In the cement industry, phosphogypsum is used as a regulator of the setting time of cement as a mineralizer in the process of calcining cement clinker. It is also utilized in the manufacturing of building materials for the production of gypsum binders and products based on them (partition walls and ceiling slabs, building blocks, putty and plaster mixes, etc.).

Japan, France, and Germany are the leading countries in terms of the development and practi- cal application of the technology of gypsum binders from phosphogypsum.

A number of studies have shown that the use of phosphogypsum in comparison with natural materials has a number of significant advantages. Long-term storage of phosphogypsum in the storage ring ensures the conversion of metastable calcium sulfates into gypsum. With the semi-hydrate decomposition of raw materials, the resulting waste in the reservoir consists predominantly of pure gypsum. In addition, in comparison with the gypsum stone of some natural deposits, phosphogypsum differs by increased dispersity and whiteness, which excludes the grinding operation and helps to improve the appearance of building products (Borowski et al. 2016).

However, there are certain disadvantages, the main of which is high and variable humidity, which varies from 20 to $40 \%$, depending on the season and the amount of precipitation. The drying process is associated with increased fuel and energy consumption, which increases the production costs. The moisture of natural gypsum stone usually does not exceed $5-8 \%$. It is important to note that due to incomplete washing, phosphogypsum contains phosphates dissolved in the liquid phase and fluorides. In the production of gypsum binders, these impurities are strong retarders of hydration processes of semi-aqueous calcium sulphate, setting and hardening of molding mixtures, which is lowered.

\section{Processing of phosphogypsum in order to extract rare-earth metal compounds}

As already mentioned, phosphogypsum is a waste originating from the processing of apatite raw materials, and, consequently, its composition includes a series of calcium-associated lanthanides. At the moment, there are a number of technologies that allow extracting rare-earth metals from this raw material. Table 2 presents the comparative characteristics of phosphogypsum with industrial rare metal raw materials used in various countries.

The authors of (Akhmetov et al. 1992) proposed a method (Fig. 1) for extracting rare-earth elements, including treatment of phosphogypsum with a solution of sulfuric acid with a concentration of $22-30$ wt. \% at liquid:solid $=1.8-2.2$ with extraction of rare-earth elements and so- 
Table 2. Mass fraction of the sum of lanthanide oxides in industrially processed ores and phosphogypsum

\begin{tabular}{|l|c|}
\hline \multicolumn{1}{|c|}{ Raw materials } & $\begin{array}{c}\text { Mass fraction } \mathrm{Ln}_{2} \mathrm{O}_{3}, \\
\%\end{array}$ \\
\hline Phosphogypsum & from 0.1 to 0.8 \\
\hline $\begin{array}{l}\text { Mountain Pass (USA), bastnesite } \\
\text { ores }\end{array}$ & from 7.0 to 10.0 \\
\hline Bayan Obo (China) & from 3.0 to 5.4 \\
\hline Loparite ores of the Kola Peninsula & from 0.3 to 0.8 \\
\hline Afrika, the Kola Peninsula & from 0.4 to 2.0 \\
\hline Canada, bastnesite ores & less than 1.7 \\
\hline Scrub-Oaks (USA), magnetite & less than 1.4 \\
\hline
\end{tabular}

dium in solution, separation of insoluble residue and crystallization of rare-earth concentrate. This method allows to achieve the recovery of rareearth elements from phosphogypsum into the concentrate in $71.4 \%$.

Additinoally, the specialists of the «Skydrade group» of companies developed a complex technology for the processing of phosphogypsum, which includes, at the first stage, separation of the group rare-earth concentrate from the sulfuric acid solution by neutralization with ammonia, and in the second stage neutralization with lime. In this case, gypsum and accompanying neutralized impurities of phosphorus and fluorine, simultaneously utilize ammonia. The mother liquor from deep neutralization was used in the head of the phosphogypsum washing process, and gypsum with calcium phosphate (tricalcium phosphate) impurities and calcium fluoride were sent to the production of binders.

\section{Processing of phosphogypsum for marketable products}

In the chemical industry, the main directions of processing phosphogypsum are as follows (Genkin et al. 2013):

- conversion with ammonium carbonate to produce ammonium sulfate and technical calcium carbonate;

- reduction firing to calcium sulfide, production of hydrogen sulfide from calcium sulfide with further processing of $\mathrm{H}_{2} \mathrm{~S}$ for sulfur;

- reduction of phosphogypsum with carbon monoxide to sulfur dioxide and its transformation into sulfuric acid;

- production of sulfuric acid and cement by firing phosphogypsum with clinker-forming additives.

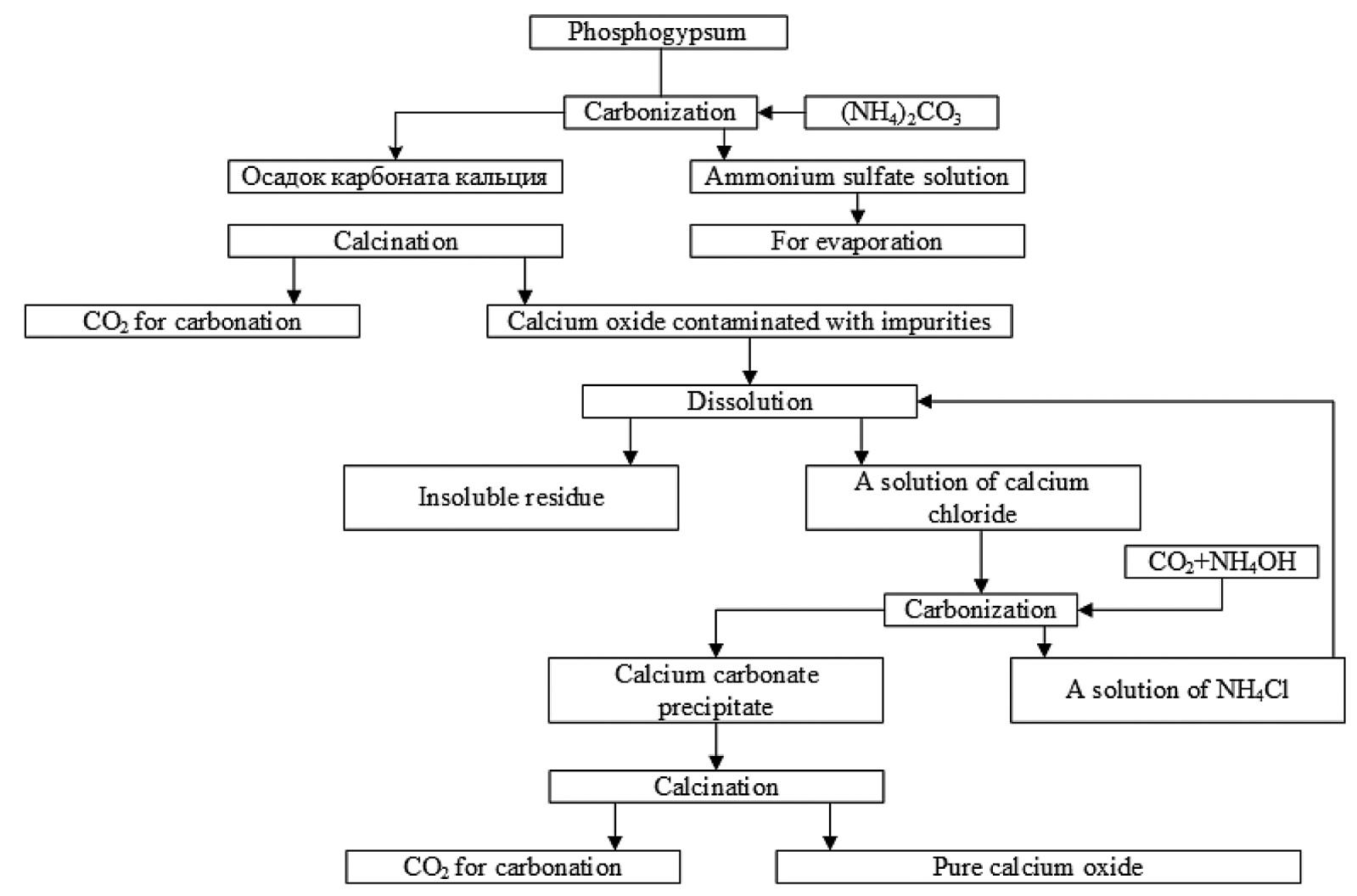

Figure 1. Technological scheme of complex processing of phosphogypsum on ammonium sulfate, calcium oxide and REE concentrate 


\section{CONCLUSIONS}

The proposed solutions for the use of phosphogypsum enable to obtain at least two products. The secondary waste generated in this case has a limited demand and practically does not find application.

The complex composition of phosphogypsum, as a raw material for the chemical industry, should be considered as an opportunity to reduce the mining development, subject it to the maximum extraction of the valuable components that make up its composition, into commodity products. The task can be successfully solved with the use of integrated processing technologies.

Thus, the factors influencing the choice of the pathway for the utilization and processing of phosphogypsum are:

- the distance from the dumps of phosofogypsum to the consumer, this is especially relevant for the agricultural direction of utilization or when it is used as raw material for the production of building materials;

- the amount of negative impurities that depends on both the feedstock and the basic technology of its processing - it is especially important when used in agriculture and for the production of consumer goods;

- the content of valuable components and the market's conjuncture - the expediency of involving the dump into deep processing depends on this;

- the availability in the immediate vicinity of the processing site of the consumer's blade of final products from the ammonium or sodium phosphate and phosphomelium conferrion.

\section{Acknowledgments}

The Common Use Centre of Mining University supported the scientific research.

\section{REFERENCES}

1. Akhmetov A.S., Dmitrieva N.V. 1992. Application of phosphogypsum in road construction. Technology of mineral fertilizers, Leningrad, 113-115.

2. Akhmetov A.S., Yarosh E.B. 1986. Technical and economic characteristics of phosphogypsum processing for sulfuric acid and binders. Technology of mineral fertilizers, Leningrad, 10-13.
3. Bazhenov Yu.M., Shubeykin P.F., Dvornik L.I. 1986. The use of industrial waste in the production of building materials. Stroiizdat, Moscow.

4. Boldyrev A.S., Losev A.N., Alekhin Yu.A. 1983. Use of waste in the building materials industry. Knowledge, Moscow.

5. Borowski G., Hycnar J.J. 2016. The effect of granulated fly ashes with phosphogypsum on the hardening of cement mortar. Technical Transactions Civil Engineering, 113, 2-B (7), 37-45.

6. Genkin M.V., Evtushenko A.V., Komkov A.A., Safiulina A.M., Spiridonov V.S., Shvetsov S.V. 2013. A method for extracting rare-earth metals and obtaining building gypsum from phosphogypsum hemihydrate. Patent RU 2187888 Russian Federation, IGC C22B 59/00, C22B 3/06.; The applicant and the patent owner United Chemical Company URALCHEM Open Joint-Stock Company - No. 2013109740/02, published on 03/03/2013, published on 20.09.2014, Bulletin No. 26.

7. Gordashevsky P.F., Dolgarev L.V. 1987. Manufacture of gypsum binders from gypsum-containing waste. Stroiizdat, Moscow.

8. Karpovich E.A., Vakal S.V., Zolotarev A.E., Sharapov S.V., Sokolovich S.A. 2008. Working off the industrial variant of technology of processing of phosphogypsum on gipseous astringent. «Ecology and health of man. Guard of air and water pools. Utilization of offcuts », Kharkov, UKNTC «Energostal». 2, 234-238.

9. Laskorin B.N., Gromov B.V., Tsyganov A.P., Sekin V.N. 1986. Wasteless technology in the industry. Stroiizdat, Moscow.

10. Medvedev A.S., Kantsel A.V. 2015. Raw materials base of rare-earth metals in Russia and variants of technological schemes for their production. Reports of the II International Scientific and Technical Conference "Modern innovative technologies for mining and processing of minerals." Publishing house "Mining book", 232-241.

11. Sizyakov V.M, Nutrihina S.V, Levin B.V. 2012. Technology of complex processing of phosphogypsum by conversion method to produce ammonium sulfate, phosphomel and new products. Journal of Mining Institute. 119, 239-244.of Economics.

12. Vereshchagin A.N. 1987. Chemical melioration of solonetzes in the steppe zone of Northern Kazakhstan. Ph.D. Thesis, Novosibirsk.

13. Volkova A.V. 2017. The market of mineral fertilizers / National Research University Higher School

14. Zinkovskaya T.S. 2010. Influence of joint application of phosphorite flour and phosphogypsum on acidic soil. Problems of reclamation of household waste, industrial and agricultural production, Krasnodar, 161-163. 